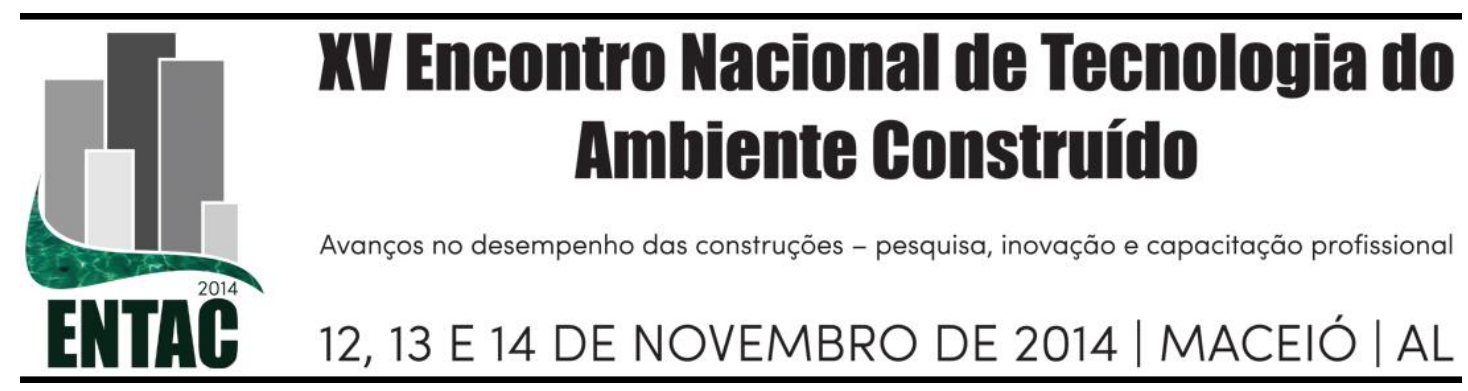

\title{
EDIFÍCIOS ALTOS: DEVEMOS CONTINUAR A EXPLORAR ESTE MODELO DE EDIFICAÇÕES?
}

\author{
SATTLER, Miguel Aloysio \\ Programa de Pós-Graduação em Engenharia Civil, UFRGS; email: masattler@ gmail.com
}

\begin{abstract}
RESUMO
O NORIE (Núcleo Orientado para a Inovação da Edificação) vem pesquisando, há quase vinte anos, um amplo espectro de temas relacionados à sustentabilidade de edificações e comunidades. Este trabalho tem por objetivo discutir alguns dos desafios relacionados a edifícios altos, particularmente daqueles já existentes e próximos de alcançar o final de sua vida útil. O método se apoia, principalmente, em revisão da literatura e discussão de alguns casos associados à realidade brasileira. A análise de perspectivas futuras e dos estoques atuais de edifícios em transição para o esgotamento de sua vida útil estimada aponta para a necessidade de nos anteciparmos ao que está sendo previsto como inevitável (esgotamento de recursos energéticos e concomitante impossibilidade de produção dos materiais que mais são utilizados atualmente na produção de edificações; a crescente degradação dos espaços urbanos; etc.), para que propiciemos uma perspectiva menos sombria a nossos descendentes, no que tange a este tema.
\end{abstract}

Palavras-chave: Sustentabilidade; vida útil de edificações; edificações altas; obsolescência de edificações.

\begin{abstract}
NORIE (Núcleo Orientado para a Inovação da Edificação) has been studying, for nearly twenty year, a broad spectrum of topics related to buildings and communities sustainability. This paper aims at discussing some of the challenges related to tall buildings, particularly of those already built and that are nearly to reach the end of their life cycle expectancy. The study makes a literature review and discusses some case studies associated to the Brazilian reality. The analysis of future scenarios and of the stock of existing buildings that are approaching the end of their life expectancy points to the necessity of taking steps towards the search for solutions to what is being forecast as inevitable (end of fossil fuels availability and the impossibility of production and replacement of most used materials in building production; the growing degradation of urban spaces; etc.), so to offer a less blight perspective to our children.
\end{abstract}

Keywords: Sustainability; life expectancy of buildings; high rise buildings; building obsolescence.

\section{INTRODUÇÃ̃o}

Acompanhando o crescimento da população mundial, particularmente nos últimos cinquenta anos, as áreas urbanas também cresceram, de modo a abrigar, hoje, mais de $50 \%$ dos habitantes do planeta. A forma de ocupação do solo nas áreas urbanas tem sido variada, com o crescimento das cidades resultando tanto em sua expansão horizontal, quanto vertical. Apenas para ilustrar extremos, na assim denominada mega-região chinesa de Hong Kong-ShenhzenGuangzhou vivem cerca de 120 milhões de pessoas; em termos de Brasil, as regiões 
metropolitanas de São Paulo e Rio de Janeiro hoje abrigam 43 milhões de pessoas, tendendo a se transformar em uma das maiores mega-regiões do mundo. Neste quadro, São Paulo é a maior cidade, ocupando uma área de 968,3 km², seguida de Brasília com 621,2 km² e Rio de Janeiro, com 557,3 $\mathrm{km}^{2}$ (SILVA, 2011). Por outro lado, também se consolidam as cidades verticalizadas, ou os núcleos de elevadíssimo índice de verticalização, em cidades de população variável, como os ocorrentes em novas cidades asiáticas e em países árabes, com prédios alcançando uma altura de até $1.000 \mathrm{~m}$. Em um e outro caso, há os defensores e críticos dessas propostas extremas.

O que se observa, em primeiro lugar, é que, para ambos os casos, seja em sua defesa ou sua crítica, apenas aspectos específicos, ou um número singelo de aspectos são analisados, sem atentar que a cidade é um "sistema complexo" e de, em decorrência disso, serem inúmeros os fatores que contribuem, ou não, para a sua sustentabilidade, saudabilidade, segurança...

Não é raro, pois, encontrar defensores da tese de que, no tocante a aglomerados urbanos, "quanto maiores, melhor...". Em sua defesa, alegam que as mega-regiões contribuem com mais de $66 \%$ de toda a atividade econômica e com $85 \%$ da inovação tecnológica e científica, e que com tais apontamentos prenunciam o potencial de consolidação e difusão dessa forma de ocupação territorial como um modelo a ser reproduzido crescentemente no futuro. Adicionam, ainda, que alguns desenhos de cidade oferecem custos maiores ou menores, conforme as suas relações de uso e ocupação, adequação topográfica, sistema viário e demais infraestruturas, entre outras condicionantes ou determinantes de projeto. Também apontam que a pavimentação e a drenagem, são as infraestruturas urbanas mais onerosas, sendo responsáveis por $55 \%$ a $60 \%$ do custo de toda a infraestrutura urbana. Neste panorama, sendo a densidade urbana a definidora dos custos de infraestrutura, o modelo de habitação multifamiliar apresenta vantagens sobre o unifamiliar, por ser o primeiro mais denso que o segundo (SILVA, 2001).

É indiscutível que haja a necessidade de se densificar áreas urbanas, pelos benefícios sociais, culturais e econômicos decorrentes e para que se evite o modelo norte-americano de subúrbios, que configura um cenário extremo de cidade dispersa. No entanto, nesta opção de densificação, existem modelos muito mais racionais (FARR, 2008), que vem propondo, desde a década de 1980, novas alternativas de dinamização urbana, diversificação e intensificação de usos e funções no solo urbano, aumento de densidade e coesão social, entre outros aspectos.

A segunda observação que se faz é que, nas análises realizadas e argumentos apresentados em defesa de cidades mais densas, raramente é incluída a discussão de cenários futuros (SUSTAINABLE CITIES INTERNATIONAL, 2012). Esta instituição (SCI) explora cenários futuros, com base nas técnicas de forecasting e backcasting. É esclarecido que forecasting é um método que permite traduzir tendências passadas e presentes em estimativas futuras. No entanto, a SCI prefere se valer do conceito de backcasting, que parte da definição de um futuro desejado (frequentemente referido como uma visão) e então avalia o que é necessário para se chegar a este futuro. Explica o problema associado com a técnica de forecasting fazendo a seguinte indagação: "Mas e se as tendências presentes forem parte do problema"? Explica que a dispersão urbana (sprawl) é um exemplo que ilustra bem a tendência de crescimento urbano, onde, se a técnica de forecasting for aplicada, ela resultará em uma predição de ainda maior dispersão urbana! Os pesquisadores atuantes na SCI afirmam que o backcasting possibilita aos planejadores a introdução de idéias criativas e novas - ampliando 
o diálogo sobre o futuro que pretendemos criar, diante de um outro, que é puramente preditivo e baseado em tendências e comportamento passados.

O autor do presente trabalho coordenou, de 1995 a 2011, a Linha de Pesquisas em Edificações e Comunidades Sustentáveis, no NORIE, e gradualmente, ampliou o foco de atuação de seu grupo de pesquisas, contemplando, consecutivamente, as áreas de materiais, edificações, bairros, cidades e, atualmente, orienta as pesquisas de sua equipe para a escala mais ampla de inteiras municipalidades. Com este foco, busca criar diretrizes para orientar o desenvolvimento de pequenas municipalidades (com menos de 20 mil habitantes), analisando, tanto as áreas urbanas, como as rurais, dentro de um enfoque sistêmico, de forma a contribuir no estabelecimento de um futuro mais sustentável e saudável. Na busca de modelos de resiliência para tais comunidades, entende que tais sistemas complexos devam ser orientados pelos princípios de sustentabilidade, em seu sentido amplo (ambiental, econômica, social, cultural, política), e dentro de um enfoque técnico, buscando harmonizar os aspectos de energia, preservação de qualidade das águas e ar, gestão de resíduos, morfologia urbana, uso do solo, drenagem urbana, produção local de alimentos e mobilidade urbana.

Neste trabalho se busca apresentar alguns dos desafios a serem enfrentados pelos vários atores da cadeia produtiva da construção civil, em especial por parte daqueles associados à produção de edifícios, particularmente no que concerne à morfologia urbana, questionando a opção que vem sendo crescentemente adotada, de edifícios altos, diante dos desafios atuais e daqueles que se anteveem ao se analisar cenários futuros.

\section{ASPECTOS PREOCUPANTES ASSOCIADOS ÀS EDIFICAÇÕES ALTAS}

\subsection{Energia}

Inúmeros especialistas na área de energia apontam para os problemas associados ao esgotamento de recursos energéticos de origem fóssil. Richard Heinberg provavelmente seja o mais popular pesquisador tratando do assunto, com vários livros publicados na área. Talvez a obra que lhe tenha conferido uma visibilidade internacional seja a intitulada The Party's Over: Oil, War and the Fate of Industrial Societies (2003). Em seu livro esclarece sobre a total dependência das modernas sociedades industriais em recursos energéticos fósseis; da preocupante falta de resiliência dessas sociedades frente a, mesmo que, diminutas reduções em recursos energéticos; da inevitabilidade da depleção de combustíveis fósseis, entre outros temas. Em uma obra mais recente (HEINBERG, 2010), o autor reafirma muitas de suas colocações, inclusive a de nossa continuada dependência em recursos fósseis, mas também destaca a curva descendente de sua disponibilidade, assim como do esgotamento de recursos em metais e minerais e, ainda, do declínio da atividade econômica global, sob muitos aspectos.

Tais eventos inevitavelmente afetarão, tanto à toda a cadeia produtiva da construção civil, altamente dependente em energia, como à própria operação das edificações, incluindo a mobilidade vertical em edifícios altos. Uma antevisão de uma situação desta natureza é muito bem ilustrada em um documentário norte americano (The Community Solution, 2006), que ilustra o colapso econômico enfrentado por Cuba, após a queda da União Soviética, quando Cuba deixou de receber metade de suas importações de petróleo. O documentário mostra claramente as dificuldades enfrentadas pelo povo cubano diante desta adversidade e, particularmente, daqueles que viviam em edificações multifamiliares, onde a falta de energia impedia o uso de elevadores, e inclusive o próprio bombeamento de água para os 
reservatórios elevados dos edifícios, o que implicava em que o acesso à água fosse realizado, pelo lado externo dos edifícios, através de sua condução em baldes, alçada aos diferentes andares por cordas, contando com o auxílio de roldanas.

Roaf et al. (2009) reforçam o primeiro destes aspectos ao lembrarem que os elevadores consomem muita energia elétrica e são caros de instalar, manter e substituir. Segundo os autores, os elevadores, sozinhos, podem representar entre 5 e $15 \%$ dos custos correntes de um prédio, e, quanto mais alto este for, mais elevados serão os custos com energia e manutenção.

Como a escassez de energia não deverá ocorrer subitamente, também a população toda não será privada dela ao mesmo tempo. Com a redução gradual dos recursos energéticos, o seu preço também se elevará gradualmente, e com isso, serão os extratos populacionais de menor poder aquisitivo os que, gradualmente, deixarão de usufruir do conforto proporcionado pelo fácil acesso à energia.

A energia do futuro certamente será de origem solar, cujo uso deverá crescer gradualmente, tanto para o aquecimento de água e do ar, como para a geração de eletricidade, na medida em que ocorrer um crescimento simultâneo na eficiência dos equipamentos que a coletam. Isto porque, em função da relativamente baixa densidade de energia presente nos raios solares, hoje a energia solar consegue suprir tão somente a energia requerida por aqueles moradores que residem diretamente abaixo do telhado que a coleta. Isto é confirmado por Roaf et. al (2009), que explicam que as características geométricas de torres (Figura 1) tornam muito difícil o uso de sistemas solares de aquecimento de água ou de geração de energia ou, ainda, de calefação, pois sua superfície não é suficiente para a suprir à totalidade dos usuários de um edifício.

\section{Figura 1 - Vista a partir de uma torre residencial no Bairro Menino Deus, em Porto Alegre}

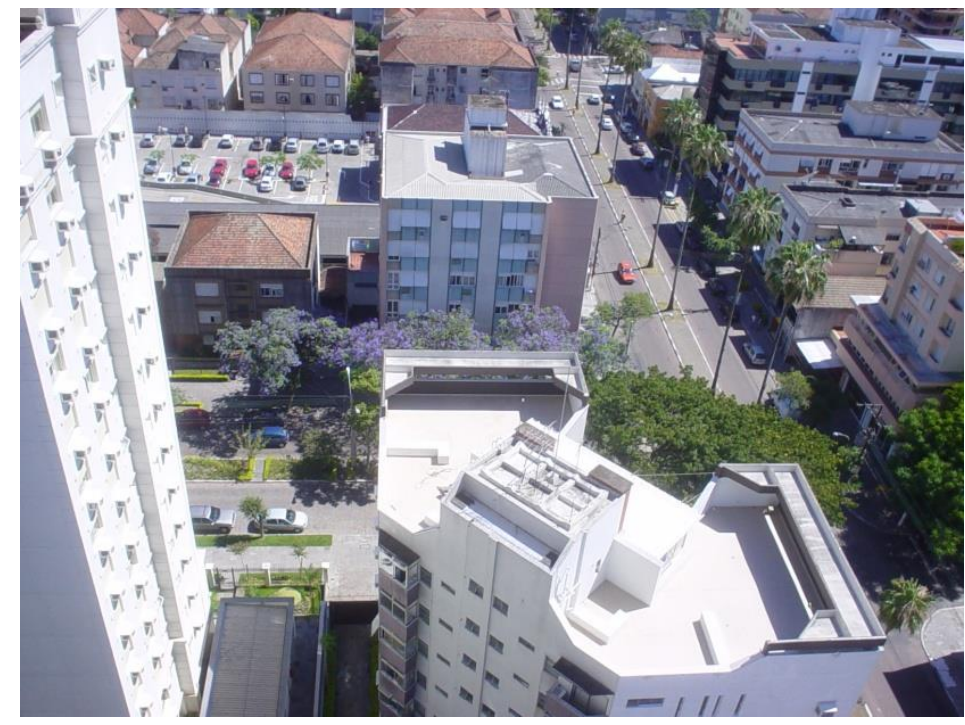

Fonte: Ingrid P. B. Bohadana (2005)

Para agravar a situação, aqueles edifícios dotados de peles de vidro também sofrem com os enormes ganhos solares, típicos de climas intertropicais, já que esta alternativa projetual dificulta o controle de ganhos solares. Tais torres, em geral, requerem sistemas de arrefecimento, pois, normalmente são dotados de uma área ampla em planta - o que ocorre 
para sua viabilização econômica - sendo impossibilitado o benefício da atenuação que poderia ser proporcionada pelo uso de ventilação natural. A climatização artificial, por si só, chega a quadruplicar os gastos com energia nessas edificações (ROAF et al., 2009).

\subsection{Durabilidade e manutenção}

A durabilidade é a capacidade de o edifício e de suas partes manterem, ao longo do tempo, o desempenho, quando expostos a condições normais de uso (JOHN; SATO, 2006). Segundo os mesmos autores, a durabilidade não é uma propriedade inerente a um material ou componente, podendo ser descrita pela variação do desempenho ao longo do tempo, ou seja, como a capacidade do produto em atender às necessidades dos usuários, que varia ao longo do tempo. Já, o desempenho é definido como a capacidade do edifício, ou de suas partes, de atender às necessidades dos usuários ou requisitos de desempenho.

Rocha (2008) ao efetuar uma revisão ampla da literatura internacional, identificou a expectativa de vida útil para as diferentes layers (estrutura, vedações, instalações e serviços e espaços internos) de uma edificação. Verificou que não há consenso quanto à longevidade associada a cada layer, apesar de sua média apontar para algo em torno de 50 anos, para a estrutura, e uma vida útil consideravelmente inferior para os demais itens, o que também está de acordo com as estimativas da NBR 15755-1 (ABNT, 2002).

Conforme a ABNT (2002), a vida útil é o período de tempo durante o qual uma edificação, sistema predial ou um componente, podem ser utilizados, sob condições satisfatórias de segurança, saúde e higiene, e a manutenção é o conjunto de atividades a serem realizadas para conservar ou recuperar a capacidade funcional de uma edificação e suas partes constituintes, para atender às necessidades e à segurança de seus usuários.

Figura 2 - Desempenho de uma edificação, ao longo do tempo

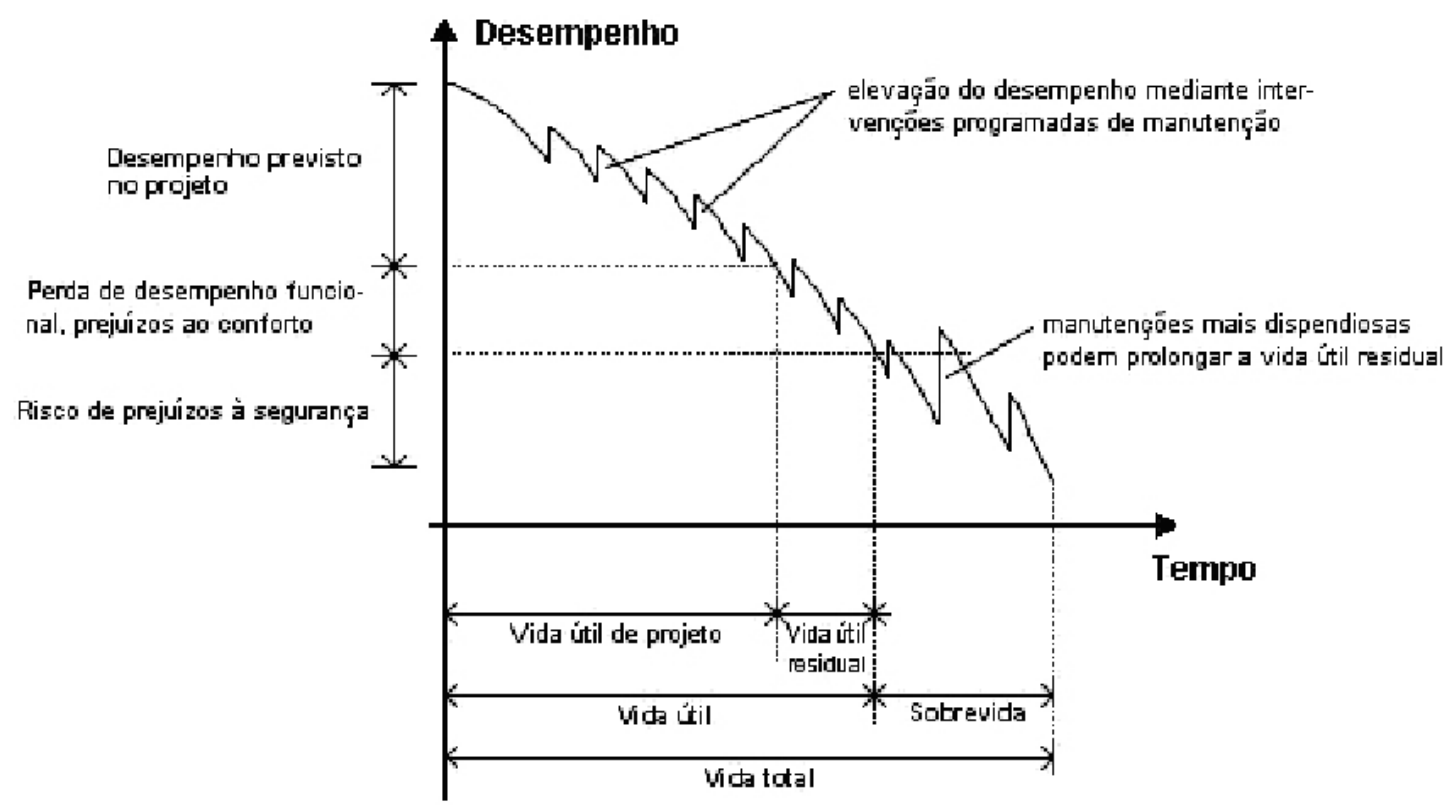

Fonte: ABNT, 2002 
Observa-se, na Figura 2, que o desempenho de uma edificação decai ao longo do tempo. Poderíamos cogitar, paralelamente, sobre a composição do perfil de renda dos moradores de tais edificações, também ao longo do tempo. Não estaria ele, de certo modo, acompanhando a curva de decaimento de desempenho ao longo do tempo e, com isso, dificultando as operações de sua manutenção? E mais: se fôssemos traçar sobre a mesma Figura 2, uma curva identificando os custos das operações de manutenção, não seria esta uma curva ascendente? E diante dessa situação não estaríamos, pelos recursos crescentes requeridos para a manutenção e disponibilidade decrescente de recursos, por parte de seus usuários, diante de um processo de esgotamento acelerado da vida útil da edificação?

Com o intuito de criar um pano de fundo para o aprofundamento desta discussão, ilustra-se, na Figura 3, dois momentos: um, identificando o final do ciclo de vida do Edifício São Vito, construído sobre um terreno de $784 \mathrm{~m}^{2}$, em São Paulo - um condomínio residencial, com 27 andares e 600 apartamentos e que foi alvo especial de atenção pelos impactos, de diversas naturezas, por um período considerável de tempo. O segundo momento registra a situação pós-demolição, com os resíduos gerados.

Com relação a este edifício, merecem destaques alguns fatos. A construção do edifício foi concluída em 1959. Em meados da década dos anos 80, ele ficou conhecido como o maior cortiço verticalizado da cidade. Em 2002, foi orçada a sua reforma: primeiro, para que o edifício pudesse ser utilizado para atender a demanda original do edifício, ou seja, para proporcionar moradia de baixo custo a usuários de baixa renda; e, mais tarde, com a finalidade de ser transformado em hotel, biblioteca ou sede de secretarias municipais. No entanto, o custo da reforma foi considerado excessivamente elevado, para tais fins. Em 2004, ele foi esvaziado, em função da precariedade de seu estado físico. Ao final, transcorreram sete anos, envolvendo tratativas judiciais, de diferentes naturezas, antes de, finalmente, ser definida a demolição do edifício, assim como de outros 33 prédios em seu entorno, incluindo ao Ed. Mercúrio, com 142 apartamentos e o Ed. Herreras, com 39 apartamentos. O processo de demolição do conjunto de prédios foi iniciado em 2010 e concluído em maio de 2011, após seis meses. Neste processo, foram gerados $45.000 \mathrm{~m}^{3}$ de resíduos e requerido um verdadeiro exército de trabalhadores.

\section{Figura 3 - Edifício São Vito, em São Paulo: (a) Edifício desocupado. (b) Resíduos, ao final do processo de demolição, dos Edifícios São Vito, Mercúrio e Herreras.}

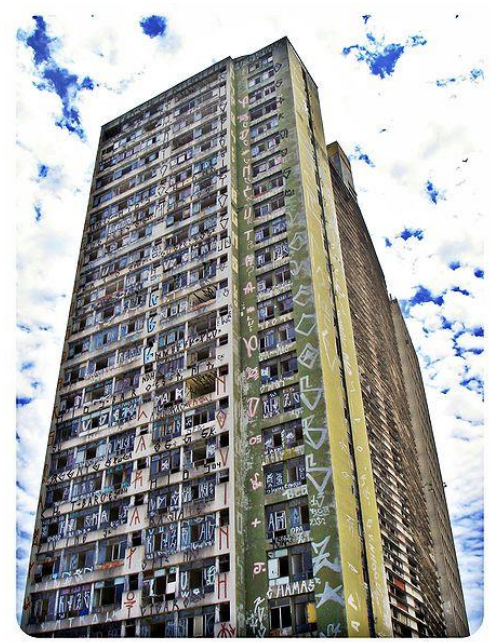

(a) Fonte: Edifício São Vito (2013)

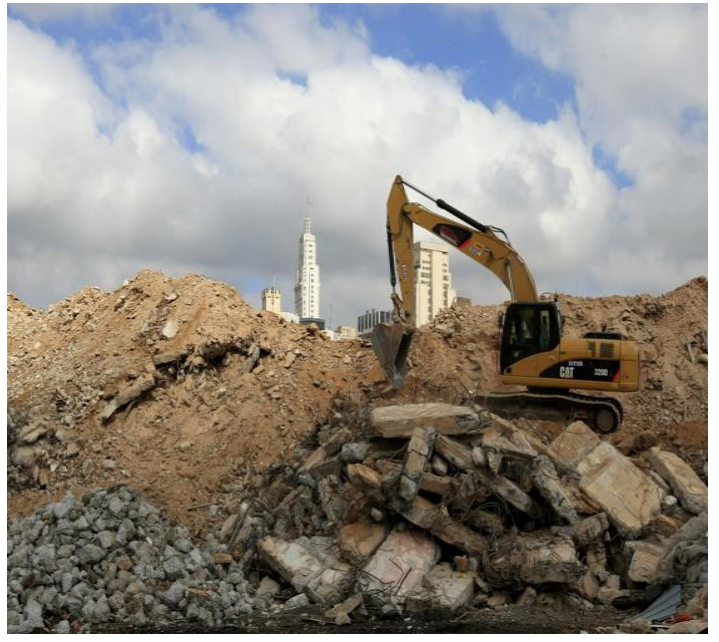

(b) Fonte: ESTADÃO.COM.BR/Blogs (2011) 
Merece destaque o fato de o processo de demolição ter sido todo custeado com recursos públicos e de o governo local ter optado por construir, no local de demolição, uma área verde, para uso público. Quantos dos prédios altos hoje existentes ou em construção, em todo o planeta, contarão com recursos para a sua demolição ao final de sua vida útil, como foi o caso aqui exemplificado? Deve-se lembrar que a demolição é um processo que requer recursos financeiros consideráveis. Normalmente, os seus usuários, por falta, ou de recursos, ou de interesse, ou, ainda, por falta de acordo entre seus proprietários, não conseguirão efetivar a sua demolição. Até porque o valor obtido, na grande maioria dos casos, com a venda do terreno sob o edifício e com a venda dos resíduos do processo de demolição, não cobriria os custos de demolição e de remoção dos resíduos. Do mesmo modo, governos locais e empresários dificilmente se disporão a custear a sua demolição. Em não havendo tal interesse o que acontecerá com os edifícios e com as áreas urbanas em que se localizam?

A mesma preocupação é manifesta por Salingaros e Kunstler (2001), quando lembram que "alguns dos edifícios mais altos, mais fortes e mesmo mais agradáveis, em termos estéticos, do início do século XX, apenas agora estão se aproximando do fim dos chamados "ciclos de vida". Qual será o destino destes prédios"?

Em um linha de pensamento afim, Roaf et al. (2009) referem que "muitas torres acabam se deteriorando de maneira lamentável, porque seus proprietários não conseguem pagar a manutenção. Aliás, há muitos exemplos que nos mostram que, muitas vezes é mais fácil dinamitá-las, do que consertá-las. Porém, inclusive esta alternativa envolve custos consideráveis e impactos ao meio ambiente".

Certamente a situação será ainda mais crítica ao se considerar que os dois panoramas acima descritos irão se sobrepor e que uma quantidade significativa de energia, escassa no futuro, também será necessária para o processo de demolição e transporte dos resíduos gerados.

\subsection{Saúde e qualidade de vida}

Algumas questões de cunho social e psicológico também devem ser incluídas em considerações sobre o tema da altura das edificações. Estudos realizados em edifícios altos, no Reino Unido, apontaram para problemas crônicos frequentes, ocorrentes em moradores de edifícios altos, como o retardo do desenvolvimento motor das crianças que não tinham a oportunidade de descer para o nível do solo, sem a presença e supervisão dos pais (ROAF et al., 2009).

Gifford (2007) também identifica distúrbios sociais e emocionais relacionados a edifícios altos, como a insatisfação, stress, problemas de comportamento, suicídio, dificuldade nas relações sociais e de desenvolvimento, em crianças.

Salingaros e Kusntler (2011) apontam ainda que, entre outros fatores, a altura dos edifícios também pode criar problemas para pessoas que sofrem de vertigem, o mal que afeta aqueles indivíduos que não têm condições psicológicas de ficar em locais "muito altos". Como questionam os autores: "Qual o portador deste problema poderia se sentir seguro e confortável trabalhando a 110 andares acima do solo? Ou a 60 andares? Ou, até, a $27^{\prime \prime}$ ?

Scussel e Sattler (2010) avaliaram o impacto do processo de verticalização e adensamento na qualidade do espaço residencial, em um bairro da cidade de Porto Alegre. Ao analisar o impacto determinado por um edifício de 18 pavimentos (Figura 
1), em um quarteirão com predominância de sobrados e prédios de três pavimentos, foi constatado que o edifício alto não somente altera a paisagem do bairro. Ele reduz (ou até exclui) a incidência de radiação solar, e o grau de privacidade das edificações vizinhas; acresce consideravelmente à densidade populacional, bem com à demanda por serviços e infraestrutura, e ao fluxo de veículos; afeta, por conseguinte, as próprias relações de vizinhança - nos novos prédios, privilegia-se a vida no condomínio, o morador já não sai à rua, os vizinhos não se conhecem. Pergunta-se, pois, até que ponto, sob tais condições, a identidade cultural do bairro pode ser sustentada? Em que magnitude se altera os aspectos de qualificação do lugar de morar de seus habitantes?

\subsection{Outros aspectos}

Não serão abordados aqui, até pela limitação de espaço, outros aspectos sobre os quais Roaf, Crichton e Nicol (2009) discorrem exaustivamente, referentes a características de edifícios altos, e que envolvem aspectos relativos à construção, uso, manutenção e impacto no entorno, entre os quais:

(a) custos de construção, operação e manutenção elevados - que crescem com a altura do edifício, por exigir sistemas construtivos e de proteção (contra incêndio, intempéries) mais complexos;

(b) no caso de inserção em áreas consolidadas - sobrecarga aos sistemas de infraestrutura urbana previamente existentes - abastecimento de água, esgotamento sanitário, energia elétrica, sistema viário - além de ampliação da demanda aos serviços e equipamentos de uso coletivo;

(c) modificação do clima local, com aumento da velocidade dos ventos ao nível da rua, sombreamento; prejuízo ao conforto térmico, lumínico e acústico, não só do entorno mas também do próprio edifício, conforme a altura e o posicionamento de determinada unidade - quanto mais alto o edifício, maior o problema de estratificação térmica e maior o consumo de energia para climatização.

\section{CONCLUSÕES}

Com base na revisão de literatura realizada e apoiado em reflexões adicionais, tendo por referência a situação brasileira, consideramos pertinentes as seguintes conclusões, que, fundamentalmente, apontam para os aspectos mais críticos associados ao processo de produção de edificações altas:

- Em primeiro lugar, o gradativo esgotamento de recursos energéticos fósseis, como apontado por Heinberg, que tornará crítica a mobilidade de seus moradores e o transporte vertical de materiais pesados de qualquer natureza;

- Em segundo lugar, com o esgotamento da vida útil deste tipo de edificações; com a concomitante diminuição da capacidade de investimentos em sua manutenção, cujos custos tendem a crescer com o envelhecimento dos edifícios; e com as dificuldades inerentes ao processo de sua demolição; antecipa-se um quadro tétrico, constituído por um crescente número de edifícios altos disfuncionais abandonados (realidade já presente em muitas cidades);

- Por último, a diminuição na saudabilidade de vida, principalmente para aqueles que mais se ressentem do problema de confinamento em edifícios altos, particularmente de crianças e idosos, depõe contra esta opção de edificação, principalmente quando destinada a moradias. 
Fica reforçada, portanto, a importância de se aprofundar e intensificar a prática de previsões do tipo backcasting, de modo a contribuir para a criação do futuro que efetivamente desejamos, particularmente no que concerne ao planejamento de áreas urbanas.

\section{AGRADECIMENTOS}

$\mathrm{O}$ autor agradece ao $\mathrm{CNPq}$ - Conselho Nacional de Desenvolvimento Científico e Tecnológico, pelos auxílios e bolsas concedidas ao mesmo, assim como a seus orientandos, tanto presentes, como passados, que lhe possibilitaram, inclusive, desenvolver os estudos constantes neste trabalho.

\section{REFERÊNCIAS}

ABNT - Associação Brasileira de Normas Técnicas (2010). Edifícios Habitacionais de até 5 pavimentos - Desempenho, Parte 1: Requisitos gerais. NBR 15755-1, Rio de Janeiro: ABNT.

EDIFÍCIO SÃO VITO (2013) Edifício San Vito. Disponível em: pt.vikipedia.org/wiki/Edificio_São_Vito. Acesso em: fev. 2013.

ESTADÃO.COM.BR/BLOGS (2011). DEMOLIÇÃO DO TREME TREME. Foto Hélvio Romero. Disponível em: blogs.estadao.com.br/olhar-sobre-o-mundo/demolição-do-tremetreme/. Acesso em: fev. 2013.

FARR, D. (2008). Sustainable Urbanism: Urban Design with Nature. Wiley, New Jersey.

GIFFORD. R. (2007). The Consequences of Living in High-Rise Buildings. Architectural Science Review. Canadá. Disponível em: http://web.uvic.ca. Acesso em: set/2012.

HEINBERG, R. (2003). The Party's Over: Oil, War and the Fate of Industrial Societies. New Society Publishers. Canada.

HEINBERG, R. (2010). Peak Everything: Waking Up to the Century of Declines. New Society Publishers. Canada.

JOHN, V.M.; SATO, N.M.N. (2006). Durabilidade de componentes da construção. In: SATTLER, Miguel Aloysio; PEREIRA, Fernando Oscar Ruttkay (editores). Construção e Meio Ambiente. Porto Alegre: ANTAC (Coletânea HABITARE, v.7).

ROAF, S.; CRICHTON, D.; NICOL, F. (2009). A adaptação de edificações e cidades às mudanças climáticas: Um guia de sobrevivência para o século XXI. Tradução Alexandre Salvaterra. Porto Alegre: Bookman, 384p.

ROCHA, C. G. (2008). Proposição de diretrizes para ampliação do reuso de componentes de edificações. Dissertação (Mestrado em Engenharia Civil) - Programa de Pós-Graduação em Engenharia Civil, UFRGS, Porto Alegre.

SALINGAROS, N.; KUNSTLER, J. H. (set. 2001). The end of tall buildings. Disponível em: <http://www.planetizen.com/node/27>. Acesso em: jul. 2012.

SCUSSEL, M. C. B.; SATTLER, M. A. (2010). Cidades em (trans)formação: impacto da verticalização e densificação na qualidade do espaço residencial. Ambiente Construído, Porto Alegre, v. 10, n. 3, p. 137-150, jul./set. 2010.

SILVA, G. J. A. (2011). Cidades sustentáveis : uma nova condição urbana - estudo de caso: Cuiabá-MT. Tese de doutorado. Universidade de Brasília, Faculdade de Arquitetura e Urbanismo, Programa de Pesquisa e Pós-Graduação em Arquitetura e Urbanismo, Brasília. 
SUSTAINABLE CITIES INTERNATIONAL (2012). Infrastructure Costs and Urban Growth Management: A practical guide to understanding the impact of urban growth patterns on a city's infrastructure costs. SCI, Vancouver.

THE COMMUnity SOlUTION (2006). The Power of Community. How Cuba Survived Peak Oil. Disponível em <www.youtube.com/watch?v=L2TzvnRo6_c>. Acesso em: fev. 2013. 